\title{
To e-bike or not to e-bike? A study of the impact of the built environment on commute mode choice in a small Chinese city
}

\author{
Yang Hu \\ Utrecht University \\ y.hu2@uu.nl \\ Dick Ettema \\ Utrecht University \\ D.F.Ettema@uu.nl
}

\author{
Anae Sobhani \\ Utrecht University \\ a.sobhani@uu.nl
}

\begin{abstract}
The use of electric bikes (e-bikes) is attracting increasing attention from researchers and policymakers as a way to promote sustainable transportation. However, knowledge about the built environment factors that influence e-bike use is lacking. In China, most evidence on e-bikes and travel behavior stems from big cities; there is much less evidence concerning small cities and their adjacent rural areas. Using travel data collected in a small Chinese city (Ganyu), the present research explores the impact of the built environment around residential and work locations on individuals' commute mode choice, with a particular focus on e-bike use. Consistent with the few previous studies on travel behavior in small Chinese cities, we find that most residents of Ganyu commute only short distances and that the e-bike is the primary mode for their daily commutes. The results of a nested logit model show that e-bike use is more popular among females and low-income groups, and that certain built environment characteristics at the work location promote e-bike use. Moreover, the built environment in different geographical contexts has different influences on commute mode choice. In particular, the presence of city/town roads without bike lanes at work locations promotes e-bike use among rural residents but much less so among urban residents.
\end{abstract}

Keywords: E-bike use, small city, urban and rural area, commute mode choice, China

\section{Introduction}

Scientists and policymakers have advocated the electrification of transportation as an effective strategy for reducing oil dependency and carbon dioxide $\left(\mathrm{CO}_{2}\right)$ emissions (Weiss, Dekker, Moro, Scholz, \& Patel, 2015). In the context of decreasing the use of petrol-and diesel-powered vehicles, the electric bicycle (e-bike) has become a successful example of electrified travel. Compared with other modes, e-bikes overcome the distance and effort barriers posed by conventional bicycles, while producing low levels of greenhouse gas emissions (de Kruijf, Ettema, Kamphuis, \& Dijst, 2018). As a sustainable and relatively

Copyright 2021 Yang Hu, Anae Sobhani \& Dick Ettema

http://dx.doi.org/10.5198/jtlu.2021.1807

ISSN: 1938-7849 | Licensed under the Creative Commons Attribution - Noncommercial License 4.0

The Journal of Transport and Land Use is the official journal of the World Society for Transport and Land Use (WSTLUR) and is published and sponsored by the University of Minnesota Center for Transportation Studies. 
fast transportation mode, the e-bike has become popular in China as a daily travel mode (Campbell, Cherry, Ryerson, \& Yang, 2016). China is the world's leader in the adoption and implementation of e-biking, accounting for more than $90 \%$ of all e-bike sales (Fishman \& Cherry, 2016).

The built environment has been found to have a significant impact on travel behavior, and it has been widely reported that densely developed, public transit-served neighborhoods and mixed land-use facilitate public transit use and active travel, while decreasing car use (Cao, 2015; Cervero, 2013; Ewing \& Cervero, 2010; Saelens, Sallis, \& Frank, 2003). The effect of the built environment on e-bike use, however, has received limited attention in the Chinese context. Very few studies have explored this aspect, and only one study (carried out in Zhongshan, China) found that within certain thresholds, employment density and land-use mix are positively associated with e-bike use (Ding, Cao, Dong, Zhang, \& Yang, 2019b).

In addition, the impact of the built environment on travel behavior may differ between geographical contexts (Gao, Kamphuis, Dijst, \& Helbich, 2018). In big Chinese cities, high population densities, mature and developed public transportation systems, and long commute distances (due to a mismatch between residential and work locations) promote public transportation use, and especially the use of the subway. By contrast, the small size and monocentric structure of small Chinese cities decrease commute distances, which leads to different mode choices in which active or semi-active travel modes (including e-bikes) play a more significant role. The use of e-bikes differs according to the urban context (big cities vs. small cities). In big cities, long commute distances make e-bikes less competitive than public transportation, whereas e-bikes are more appealing in small cities, as a small-scale built environment and short commute distances are more conducive to the use of these semi-active travel modes. Another relevant aspect in smaller cities concerns the interaction with rural areas adjacent to them, which leads to specific travel patterns.

Most Chinese studies of land-use-transportation interaction address big cities, and limited attention has been paid to small cities and their adjacent rural areas, where the available travel modes and built environment context are markedly different. To some degree, existing insights from big Chinese cities are not representative of other parts of China. Meanwhile, small cities are surrounded by large rural areas, and the travel patterns of rural residents are distinct from those of urban residents.

In order to explore this difference and establish what mechanisms influence travel behavior in urban and rural contexts, the present research investigated the impacts of the built environment on commute mode choice in Ganyu, a small city in eastern China. The focus was on e-bike use and how socioeconomics and the built environment around residential and work locations influence individuals' commute mode choice.

\section{$2 \quad$ Literature review}

\subsection{E-bike use in China}

E-biking is similar to conventional cycling in terms of steering, interaction with other road users, and exposure to the environment, but requires less or no effort, as e-bikes are equipped with integrated electric motors. In China, e-bikes can be divided into two types: bicycle-style e-bikes and scooter-style e-bikes (see Figure 1) (Fishman \& Cherry, 2016). The former need pedal assistance, while the latter are powered only by an electric motor that is activated by a hand-operated throttle. A new style of e-bike (c in Figure 1) that combines the characteristics of scooter-style and bicycle-style e-bikes was recently launched on the Chinese market. All three types are commercially available in China, but the "combina- 
tion style" e-bikes are more popular, as they combine the benefits of the other two styles. According to Chinese traffic regulations, e-bikes are classified as bicycles and should be ridden in bike lanes, and their top speed has to be less than $20 \mathrm{~km} / \mathrm{h}$ (Administration of Quality Supervision of China, 1999; Fishman $\&$ Cherry, 2016). As there are no bike lanes in some areas, e-bikes usually share the road with cars and bicycles, which increases the chance of accidents (Cherry, Weinert, \& Xinmiao, 2009; Lan, Liem, \& Binh, 2013).

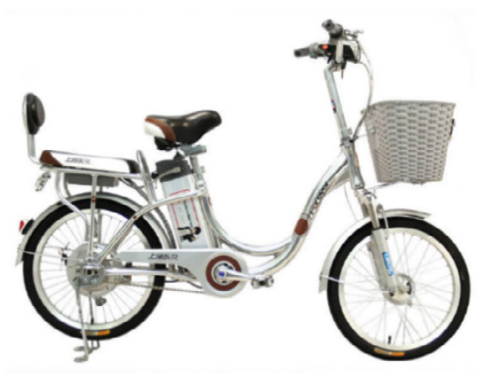

a) Bicycle-style e-bike

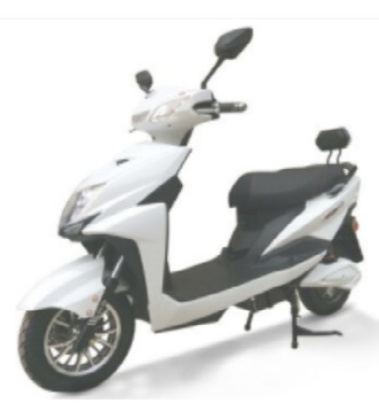

b) Scooter-style e-bike

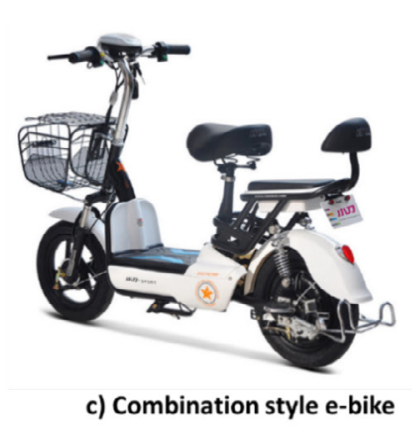

Figure 1. E-bike styles (source: $\underline{\text { https://item.jd.com/, https://product.suning.com/) }}$

In North American and European contexts, e-bikes are more favored by the elderly or people with physical limitations that prevent them from cycling (Fishman \& Cherry, 2016). By contrast, in China, it is a popular travel mode among all age groups. This is related to car ownership rates in China, which are still markedly lower (15\%) than in most European countries (50\%) (European Environment Agency, 2018; Ministry of Public Security of China, 2019). In addition, e-bikes cost less than RMB 3000 (approximately USD 400), which is affordable to most Chinese people, whose average annual income is more than RMB 25,000 (National Bureau of Statistics of China, 2018). The relatively low price, the limited effort required to ride an e-bike, and the higher speed compared to conventional bicycles contribute to the popularity of e-bike use in China. More than 250 million Chinese individuals use e-bikes (Hu, Xu, Shen, Shi, \& Chen, 2018; Zhang, 2018).

In China, the e-bike is becoming a competitive travel mode. Studies conducted in two big Chinese cities (Kunming and Shanghai) found that e-bikes were effectively replacing cars, as more than $40 \%$ of e-bike users also had household car access (Cherry, Yang, Jones, \& He, 2016). Moreover, conditions such as high temperatures, precipitation, and poor air quality stimulate individuals to choose e-bikes rather than bicycles, which was evidenced in Beijing (Campbell et al., 2016). However, few studies have explored the impact of the built environment on e-bike use. One recent study found that there is a nonlinear relationship between built environment elements and e-bike ownership (Ding, Cao, Dong, Zhang, \& Yang, 2019a): Within certain thresholds, longer distance to public transit, higher employment density, and more mixed land-use were associated with higher e-bike ownership levels. However, that research focused only on e-bike ownership and did not consider e-bike use in the travel mode choice.

\subsection{Commute mode choice studies in China}

Travel behavior in Chinese cities has received much attention over the last decade, due to the transformation of the travel behavior of residents resulting from unprecedented urbanization and the rapid development of urban transportation systems. Consistent with literature on North American and European contexts, studies in China show that higher residential density and mixed land-use decrease commute 
distance and facilitate non-motorized travel (Wang \& Zhou, 2017). In addition, specific Chinese forms of planning have been found to affect travel behavior. For example, in the traditional and unique danwei (work unit) housing system, state-owned enterprises provide housing for workers near their workplaces, and thus these employees commute only very short distances and are more likely to choose active commute modes (Wang \& Chai, 2009; Zhang, Chen, Huang, \& Yu, 2014). However, the impact of the danwei housing system is ebbing away with the advancement of Chinese marketization reform.

As a trip is a movement from the point of origin to a destination, it is likely that the built environment surrounding these two locations could affect the trip behavior. However, in Chinese land-usetransportation interaction research, most studies have focused on the built environment at residential locations (Feng, 2017; Feng, Dijst, Wissink, \& Prillwitz, 2014; Li \& Zhao, 2017; Zhao, Nielsen, Olafsson, Carstensen, \& Meng, 2018), and very limited attention has been paid to the built environment at both the residential location/origin and the workplace/destination. The built environment at these two locations could exert different influences on an individual's travel behavior. Evidence from Shanghai showed that the built environment at the residential location has a stronger influence on commute mode choice than the built environment at the work location, in which the proportion of residential density, road density, and four-way intersections at residential locations was negatively associated with commuting by car (Sun, Ermagun, \& Dan, 2017). Another study conducted in Beijing found that population density at residential locations is negatively associated with an individual's commute mode choice of car, while a higher density of jobs at work locations encourages commuters to choose motorized rather than non-motorized transportation modes (Zhao, 2013).

\subsection{Travel behavior in big cities, small cities, and rural areas}

Differences between the socioeconomic and built environments in big versus small cities lead to individuals living in those areas having different travel patterns. Big cities have a higher population density, a more rapid pace of life, and a busier flow of population in daily life, and their public transportation systems are completer and more mature; thus, more trips in big cities are made by public transportation. In New York City, for example, more than $60 \%$ of commutes are made by public transit (Goetzke, 2008). Compared with big cities, small cities have lighter traffic and stronger social connections among their residents. Public transit service in small cities is more limited, and short-distance travel modes—such as by bike-is more appealing (Handy, Heinen, \& Krizek, 2012). Concerning differences in travel patterns between big cities and small cities, some European studies (e.g., from the Netherlands and Germany) found that when city size increases, the share of trips by public transportation increases and the share by car decreases (Scheiner, 2010; Susilo \& Maat, 2007). However, this is not a clear-cut conclusion regarding the use of non-motorized travel modes in cities of different sizes. For instance, Schwanen (2002) found that modal share by bicycle and foot decreases when city size increases, while Scheiner (2010) found that the share of trips of less than $1.5 \mathrm{~km}$ by bicycle and foot increases when city size increases.

Rural areas have a lower population density than urban areas and the travel patterns of rural residents differ from those of urban residents. In North America, for example, more than $90 \%$ of people in rural areas choose to travel by car, regardless of their age, income, or race (Pucher \& Renne, 2005). Similarly, in western Europe-despite having more compact land-use patterns and a more developed public transportation system than the US — cars still play a vital role in commuting in both rural and suburban areas. For example, a study conducted in Spain found that more than $60 \%$ of the residents of suburban areas of Barcelona chose to commute by private car (Asensio, 2002). 


\subsection{Commute mode choice in small Chinese cities and rural areas}

In China, a small city is defined as a city with fewer than 500,000 residents (State Council of China, 2014). Like all cities, small cities have evolved from towns, but—unlike large cities—-they still have a monocentric spatial configuration, with a concentration of public facilities in their centers ( $\mathrm{Hu}$ et al., 2018). Due to ongoing urbanization in China, cities become developed areas and attract more affluent individuals, and usually have higher levels of car ownership. In such cases, urban residents are more likely than rural residents to travel by car. The increase in car use in cities results in more traffic and sometimes traffic congestion. This issue is being tackled in some cities by the extensive provision and promotion of public transportation. However, public transportation systems in small cities tend to be undeveloped and inefficient, and thus fail to meet the rising demand for public transportation (Hu et al., 2018; Ling, Cherry, Yang, \& Jones, 2015; Wan, Wang, \& Sperling, 2013; Wang, Chai, \& Li, 2011). Some research even shows that the public transportation modal share is less than $10 \%$ in small Chinese cities (Hu et al., 2018). On the other hand, in small Chinese cities, the small-scale spatial environment and monocentric structure decrease commute distance, and the e-bike has become an appealing, reliable, and convenient travel mode choice. E-bikes are competitive with cars, especially where the speed of cars is restricted by traffic congestion.

Research on travel behavior in small Chinese cities is very limited, and to the best of our knowledge there has been only one relevant finding, namely that in Changting (a small city in Fujian province), land-use diversity at work locations increased the number of bus rides and reduced the propensity to drive to work on weekdays (Hu et al., 2018). However, Changting is in a mountainous area and is thus not representative of all small cities in China.

Commute mode patterns in Chinese rural areas differ from those in urban areas: Less than $20 \%$ of commutes are by car (Yang, Yuan, \& Feng, 2014). This is probably due to the low level of car ownership in Chinese rural areas. In the context of ongoing urbanization in China, more individuals are migrating to cities, and those who remain in rural areas tend to be people with low incomes who thus cannot afford cars. In this context, rural residents usually work near their homes and commute only short distances, and therefore travel on foot or by bike, e-bike, or motorbike.

\section{$3 \quad$ Methodology}

\subsection{Study area}

Ganyu is a small coastal and plain city in eastern China. The city regional area, of which less than $10 \%$ is mountainous, covers $1514 \mathrm{~km}^{2}$ and consists of two parts: an urban area—Ganyu city—and a rural area (see Figure 2). Ganyu city has a land area of less than $100 \mathrm{~km}^{2}$ and about 200,000 inhabitants. The villages and towns outside the city are classified as rural (Lianyungang Bureau of Statistics, 2018). The urban area is, of course, more developed: It has a high-density population, compact land-use, and good municipal facilities in the city center. In recent years, the city has been spreading toward the east, increasing residents' commute distance to some degree and thus leading to more private car use. However, most people prefer to live and work in the central urban area, and most of them travel only a short distance (less than $4 \mathrm{~km}$ ) to work. By definition, the rural area is less developed and has a low population density, and some of the roads are not good enough for commuting. 


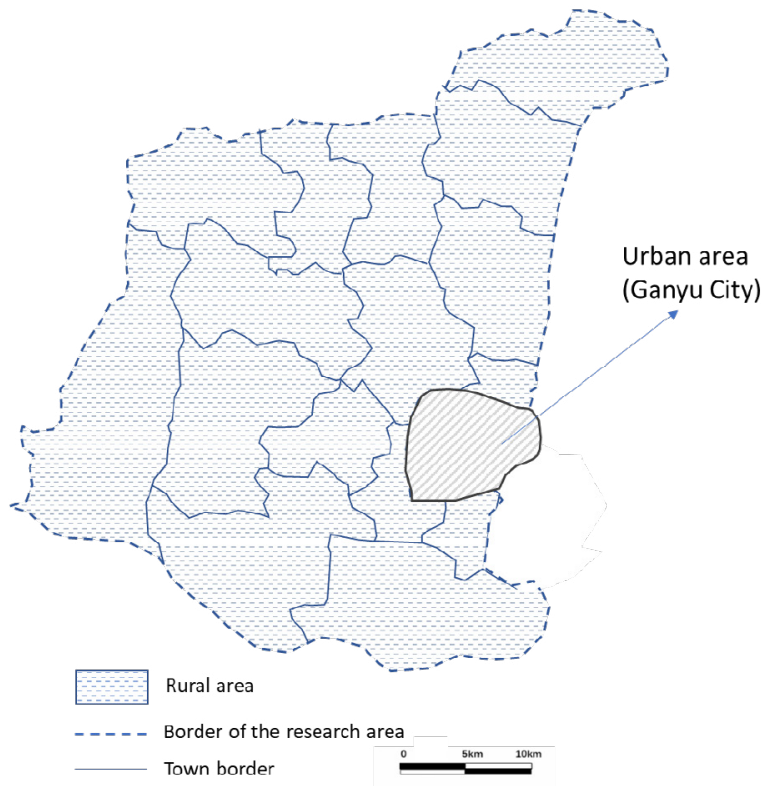

Figure 2. Urban and rural areas in Ganyu

\subsection{Survey designs}

To investigate commute mode choice in Ganyu, a survey was carried out with the help of local schools; that is, teachers asked their students to get one of their parents to complete a questionnaire. As we had insufficient resources to conduct a strict sampling process, a survey via schools was a good way to acquire travel data. Before the survey, we had no idea how many people would complete the questionnaire. In order to get a larger sample size for the analysis, and based on the number of teachers and schools that were willing to help conduct the survey, in January 2018, 1800 questionnaires were distributed in four educational institutes in Ganyu, namely a kindergarten, a primary school, a junior high school, and a senior high school. The four schools are in the urban area, but a great number of students at the senior high school live in a rural area, which enabled us to acquire information about rural residents. Of the 1800 questionnaires, 600 were distributed to urban residents and 1200 to rural residents. The questionnaire contained questions concerning socio-demographics (gender, age, education degree, annual household income, household size, car ownership, driving license possession, going home for lunch, and working period during the day), commute mode choice, and residential and work location addresses. ${ }^{1}$

The survey response rate was $57.3 \%$. However, only questionnaires that provided full travel information and valid residential addresses were regarded as valid responses, resulting in a $37.8 \%$ valid response rate, namely $71.5 \%$ (429 respondents) in the urban area and $21.0 \%$ ( 252 respondents) in the rural area. There was a low response rate in the rural area because the parents of some students are migrant workers and are often away for long periods, which means they were unable to complete the questionnaire. In addition, students from the rural area only see their parents when they go home at weekends, which delayed and impeded an effective response from their parents. Only respondents who provided accurate residential and work locations were included in the analysis, which resulted in a final sample size of 459 respondents ( 325 from the urban area, 134 from the rural area). The sample size is not very big, but was sufficient for the analysis, as shown by the significant effects that we found (Table 3).

${ }^{1}$ The questionnaire included more questions; only the questions used for this study are described in this paper. 
In addition, land-use and road attribute data were acquired from the maps of Ganyu city and towns in the rural area, and from satellite map images. For built environment attributes, 500-meter radius buffers at both the residential and the work location of each respondent were constructed to capture the percentage of various types of land use, road length, and road intersections. Land-use type was categorized into residential, commercial, industrial, or services. Services refers to services for individuals and includes offices, hospitals, schools, and other public services. Roads were also categorized into four types: major trunk roads, city/town roads without bike lanes (RNBs), city/town roads with bike lanes (RBs), and foot/bike paths. Major trunk roads refer to trunk roads across the city-regional area, and they are mainly, but not only, used by motorized vehicles. RNBs are secondary roads, in both urban and rural areas, without bike lanes. RBs are secondary roads with bike lanes alongside them, and they are concentrated in the urban area. Foot/bike paths are narrow lanes or minor roads suitable for walking and cycling. Road intersections were categorized as either "active travel intersections" or "other." The former facilitate active travel modes; that is, they are intersections of an RNB and a foot/bike path, an RB and an RB, an RB and a foot/bike path, a foot/bike path and a foot/bike path, or an RB and an RNB.

Travel time (trip variables) for each individual were acquired from Gaode Map. As Gaode Map only provides these data for four transportation modes (foot, bike, car, and bus), travel time by e-bike was calculated manually, based on travel time by bicycle and the ratio of the average speed of an e-bike and a bicycle (14.5 km and $11 \mathrm{~km}$ per hour, respectively) in the Chinese context (Cherry, 2007). 
Table 1. Variables used in the model

\begin{tabular}{|c|c|c|c|}
\hline Variable & Explanation & \multicolumn{2}{|c|}{ Percentage } \\
\hline \multicolumn{4}{|l|}{ Trip variables } \\
\hline TT & Travel time (mins) for each mode & \multicolumn{2}{|l|}{-} \\
\hline \multicolumn{4}{|l|}{ Socioeconomic variables } \\
\hline \multicolumn{4}{|l|}{ Location of residence } \\
\hline Urban & & \multicolumn{2}{|l|}{$70.8 \%$} \\
\hline Rural & & \multicolumn{2}{|l|}{$29.2 \%$} \\
\hline \multicolumn{4}{|l|}{ Gender } \\
\hline Male & & \multicolumn{2}{|l|}{$37.7 \%$} \\
\hline Female & & \multicolumn{2}{|l|}{$62.3 \%$} \\
\hline \multicolumn{4}{|l|}{ Age } \\
\hline $25-35$ years old & & \multicolumn{2}{|l|}{$14.6 \%$} \\
\hline $36-45$ years old & & \multicolumn{2}{|l|}{$64.5 \%$} \\
\hline$>45$ years old & & \multicolumn{2}{|l|}{$20.9 \%$} \\
\hline \multicolumn{4}{|l|}{ Education degree } \\
\hline High & College degree or above & \multicolumn{2}{|l|}{$47.3 \%$} \\
\hline Low & No college degree & \multicolumn{2}{|l|}{$52.7 \%$} \\
\hline \multicolumn{4}{|l|}{ Income } \\
\hline$<$ RMB $50 \mathrm{k}$ & Annual household income & \multicolumn{2}{|l|}{$20.7 \%$} \\
\hline RMB $50 \mathrm{k}-100 \mathrm{k}$ & Annual household income & \multicolumn{2}{|l|}{$54.2 \%$} \\
\hline$>$ RMB $100 \mathrm{k}$ & Annual household income & \multicolumn{2}{|l|}{$25.1 \%$} \\
\hline \multicolumn{4}{|l|}{ Household size } \\
\hline 3 or fewer & 3 or fewer family members & \multicolumn{2}{|l|}{$16.3 \%$} \\
\hline 4 or more & 4 or more family members & \multicolumn{2}{|l|}{$83.7 \%$} \\
\hline \multicolumn{4}{|l|}{ Return home for lunch } \\
\hline Eat at home & Individuals go home for lunch & \multicolumn{2}{|l|}{$70.4 \%$} \\
\hline Not eat at home & Individuals do not go home for lunch & $29.6 \%$ & \\
\hline Land-use attributes around & and work locations (500-meter buffer) & Home & Work \\
\hline Residential area & & & \\
\hline Residential $(\geq 70 \%)$ & Residential area/ total area of various land uses $(\geq 70 \%)$ & $67.1 \%$ & $44.2 \%$ \\
\hline Residential $(<70 \%)$ & Residential area/ total area of various land uses $(<70 \%)$ & $32.9 \%$ & $55.8 \%$ \\
\hline Service area & & & \\
\hline Service $(\geq 13 \%)$ & Service area/ total area of various land uses $(\geq 13 \%)$ & $35.1 \%$ & $53.6 \%$ \\
\hline Service $(<13 \%)$ & Service area/ total area of various land uses $(<13 \%)$ & $64.9 \%$ & $46.4 \%$ \\
\hline Commercial area & & & \\
\hline Commercial $(\geq 15 \%)$ & Commercial/ total area of various land uses $(\geq 15 \%)$ & $12.9 \%$ & $24.2 \%$ \\
\hline Commercial $(<15 \%)$ & Commercial/ total area of various land uses $(<15 \%)$ & $87.1 \%$ & $75.8 \%$ \\
\hline Industrial area & & & \\
\hline Industrial $(\geq 10 \%)$ & Industrial/ total area of various land uses $(\geq 10 \%)$ & $13.1 \%$ & $20.5 \%$ \\
\hline Industrial $(<10 \%)$ & Industrial/ total area of various land uses $(<10 \%)$ & $86.9 \%$ & $79.5 \%$ \\
\hline Road type attributes aroun & and work locations (500-meter buffer) & & \\
\hline Major trunk road & & & \\
\hline Major trunk road $(\geq 10 \%)$ & Major trunk road length/ total road length $(\geq 10 \%)$ & $12.9 \%$ & $29.8 \%$ \\
\hline
\end{tabular}




\begin{tabular}{|c|c|c|c|}
\hline \multirow{2}{*}{$\begin{array}{l}\text { Variable } \\
\text { Major trunk road }(<10 \%)\end{array}$} & \multirow{2}{*}{$\begin{array}{l}\text { Explanation } \\
\text { Major trunk road length/ total road length }(\geq 10 \%)\end{array}$} & \multicolumn{2}{|c|}{ Percentage } \\
\hline & & $87.1 \%$ & $70.2 \%$ \\
\hline \multicolumn{4}{|l|}{ RNB } \\
\hline RNB ( $\geq 50 \%)$ & $\begin{array}{l}\text { City/town road without bike lane length/ total road length } \\
(\geq 50 \%)\end{array}$ & $34.4 \%$ & $49.2 \%$ \\
\hline RNB $(<50 \%)$ & $\begin{array}{l}\text { City/town road without bike lane length/total road length } \\
(<50 \%)\end{array}$ & $65.6 \%$ & $50.8 \%$ \\
\hline \multicolumn{4}{|l|}{$\mathrm{RB}$} \\
\hline $\mathrm{RB}(\geq 15 \%)$ & City/town road with bike lane length/ total road length $(\geq 15 \%)$ & $47.9 \%$ & $36.6 \%$ \\
\hline $\mathrm{RB}(<15 \%)$ & City/town road with bike lane length/ total road length $(<15 \%)$ & $52.1 \%$ & $63.4 \%$ \\
\hline \multicolumn{4}{|l|}{ Foot/bike path } \\
\hline Foot/bike path $(\geq 35 \%)$ & Foot/bike path length/ total road length ( $\geq 35 \%)$ & $57.1 \%$ & $48.4 \%$ \\
\hline Foot/bike path $(<35 \%)$ & Foot/bike path length/ total road length $(<35 \%)$ & $42.9 \%$ & $51.6 \%$ \\
\hline \multicolumn{4}{|l|}{ Active travel intersection } \\
\hline Active travel intersection $(\geq 75 \%)$ & Active travel intersection/ total road intersection $(\geq 75 \%)$ & $70.6 \%$ & $50.1 \%$ \\
\hline Active travel intersection $(<75 \%)$ & Active travel intersection/ total road intersection $(<75 \%)$ & $29.4 \%$ & $49.9 \%$ \\
\hline
\end{tabular}

\subsection{Modelling approach}

A nested logit (NL) model was used to identify factors that affect commute mode choice, as an NL model is suitable for addressing collinearity among alternatives (Koppelman \& Bhat, 2006; Wen, Wang, $\& \mathrm{Fu}, 2012)$. Many types of nested structures were tested, but car and e-bike in one nest was the most suitable (see Figure 3). The explanatory variables were commute mode choices; independent variables were trip attributes, individual's socioeconomic attributes, land use, and road type factors (see Table 1). With regard to the classification of the land use and road type, a logical cutoff point was based the local context and model results. Given the local context, we tried various thresholds starting from median values, and finally identified and used those cutoff points (see Table 1) that led to better model results (i.e., a smaller absolute value of loglikelihood and more significant variables).

As the analysis involved both urban and rural contexts, we took into account that factors that influence commute mode choice might have different effects in these two contexts. Interaction items in the regression would be able to capture how one independent variable has an impact on a dependent variable, depending on another independent variable (Aiken, West, \& Reno, 1991; Cleary \& Kessler, 1982). To differentiate the impact of factors in the urban and the rural context, each variable (see Table 1), except "Location of residence," was multiplied by the "urban" attribute to get new interaction items with urban. During the specification, the independent variables were those listed in Table 1 and interaction items.

As the share of motorcycle use was $2.4 \%$, which was too small, and the motorcycle is regarded as a motorized vehicle in China, we merged motorcycle into the car group. Moreover, the model considered the availability of each mode. That is, a car was considered available when a respondent owned a car and held a driving license, and a bus was available when the Gaode map provided a bus route between an individual's residential and work locations. If the travel distance is too short or there is no bus route between origin and destination, the map does not automatically provide any bus route plan. As e-bikes and bikes are not expensive in China and are therefore affordable to everyone, we assumed that everyone had access to a bike and an e-bike. In addition, transport on foot is available to everyone.

During specification, variables were entered into the model step by step, while variables with coef- 
ficients not significant at the level of $t>1.5$ were excluded. The software package Pandas Biogeme was used for the model estimation, and the dissimilarity parameter was estimated as 0.61 , which is within the acceptable interval range (from 0 to 1 ) of this parameter for the nested model.

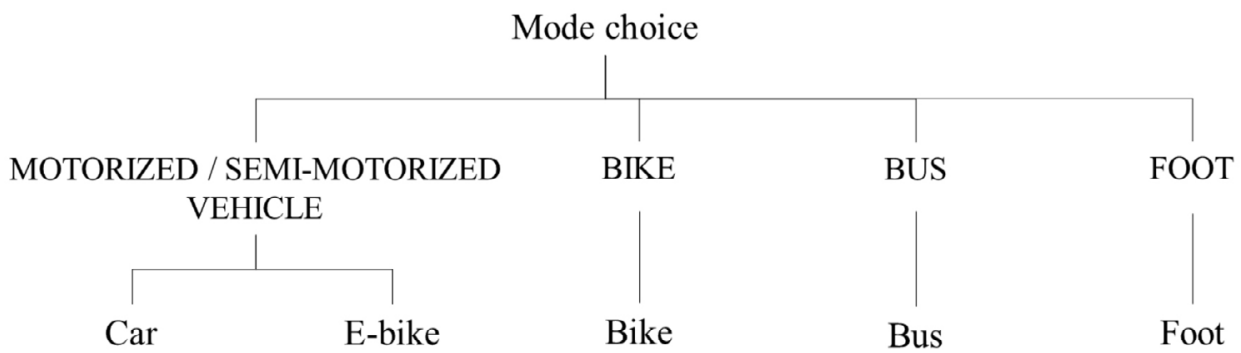

Figure 3. Nested logit structure

\section{$4 \quad$ Results}

\subsection{Descriptive analysis}

The e-bike (48.1\%) is the dominant commute mode, followed by the car $(31.4 \%)$. This is consistent with the findings in another small city in China (Hu et al., 2018). The bus is less popular: Only $4.8 \%$ of residents commute by bus. This differs from the situation in big cities in China, where public transportation is the dominant travel mode (Mao, Ettema, \& Dijst, 2016; Sun et al., 2017). Not many urban or rural residents choose walking (12.0\%) or cycling (3.7\%) for their commutes (see Table 2).

As for the difference in the mode shares between urban and rural areas, the percentage of e-bike commutes in both areas is almost the same ( $48.6 \%$ and $47 \%$, respectively). This also applies to bus commutes (4.6\% and 5.2\%, respectively). More rural residents walk to work (23.1\%) compared to urban residents $(7.4 \%)$. In addition, the car mode share is much higher in the urban area (34.8\%) than in the rural area $(23.1 \%)$, which is consistent with lower levels of car ownership in Chinese rural areas. Finally, more people in the urban area (4.6\%) than in the rural area (1.5\%) cycle to work (see Table 2).

Table 2. Commute mode share in urban and rural areas

\begin{tabular}{|l|l|l|l|}
\hline & Urban & Rural & Total \\
\hline Foot & $7.4 \%$ & $23.1 \%$ & $12.0 \%$ \\
\hline Bus & $4.6 \%$ & $5.2 \%$ & $4.8 \%$ \\
\hline Car & $34.8 \%$ & $23.1 \%$ & $31.4 \%$ \\
\hline E-bike & $48.6 \%$ & $47.0 \%$ & $48.1 \%$ \\
\hline Bike & $4.6 \%$ & $1.5 \%$ & $3.7 \%$ \\
\hline Total & $100.0 \%$ & $100.0 \%$ & $100.0 \%$ \\
\hline
\end{tabular}

As regards the travel time of each resident's selected commute mode, the travel time by bus is very long-namely more than 68 minutes for both urban and rural residents-while for the other four modes it is less than 20 minutes (see Figure 4). Moreover, there is not much difference between rural 
and urban residents in terms of travel time for all the modes except e-bike; that is, rural residents who choose e-bikes for commuting have a long travel time. In addition, the average commute duration in our sample was 13.6 minutes, which is much shorter than in big cities in China (e.g., 39.2 minutes in Shanghai; Sun et al., 2017).

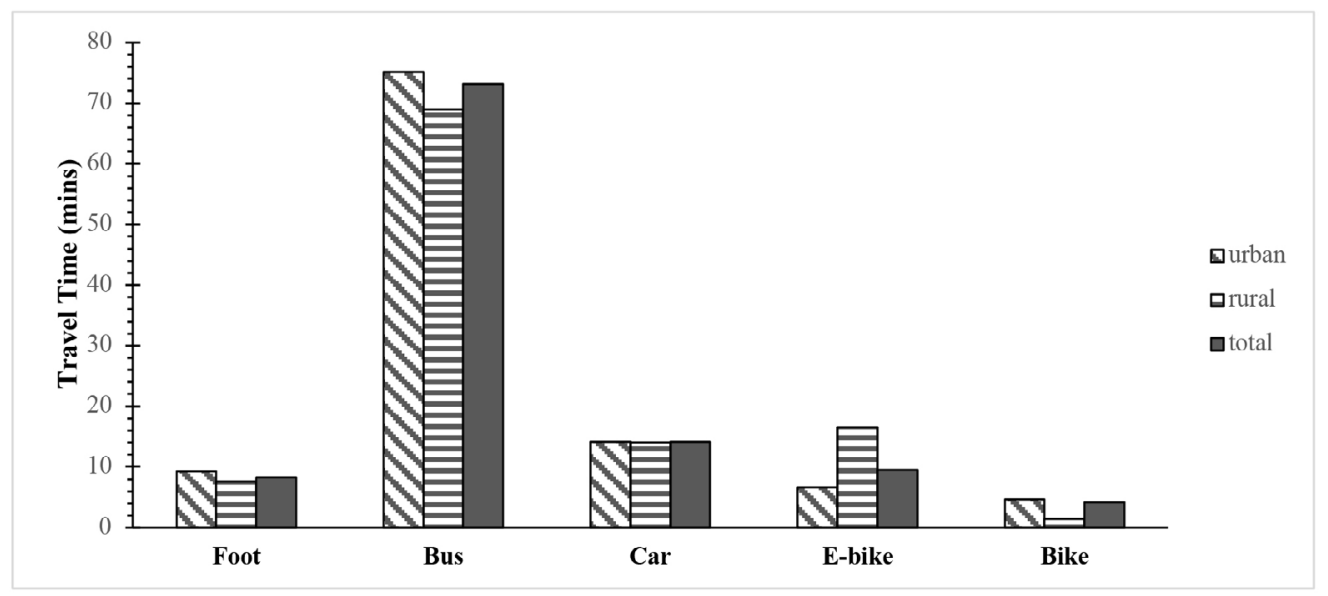

Figure 4. Travel time for each mode distribution in Ganyu

The trips of respondents who reported departure time from both home and work were included in the analysis (1,366 trips reported by 408 respondents). There are three peak periods, namely the morning peak (07:30-08:30), the lunchtime peak (11:30-12:00 and 14:00-14:30), and the evening peak (17:00-18:30) (see Figure 5). This distribution is very different from the situation in big cities in China, which have only two peak periods (i.e., no lunchtime peak) (Wang, Fu, Zhou, \& Li, 2008; Zhang, Yao, Zhang, \& Xu, 2019). The lunchtime peak is verified by another variable's statistics in our sample, namely that $70.4 \%$ of residents go home for lunch.

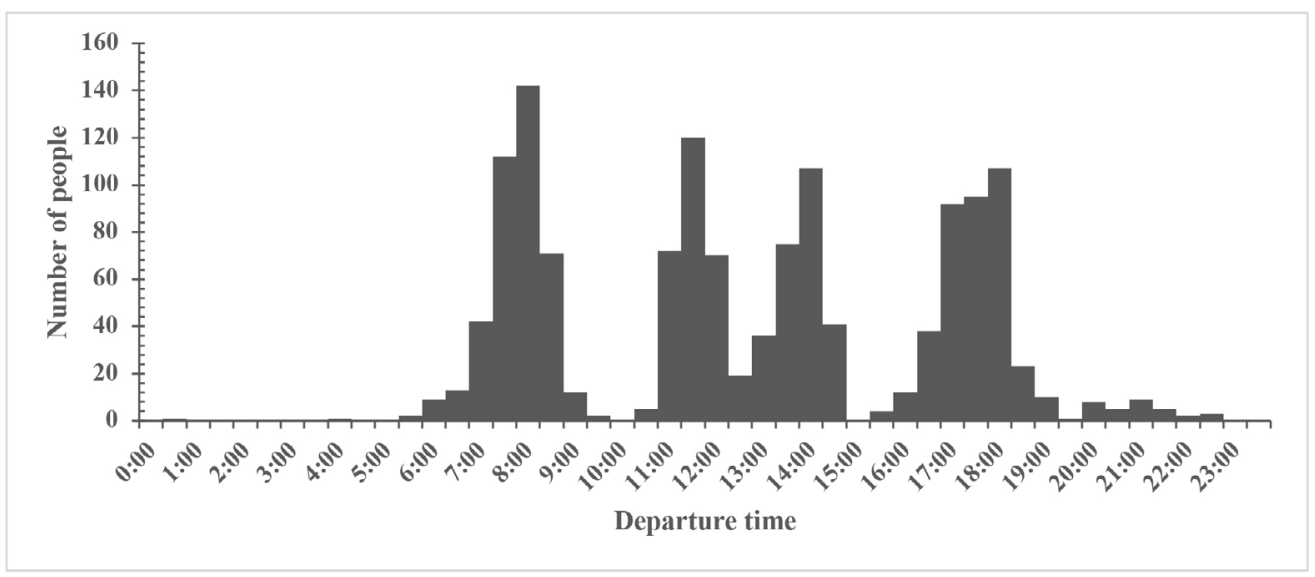

Figure 5. Departure time distribution in Ganyu

In the urban context, more female than male residents choose e-bikes and bikes for commuting, while there is not much difference in the share of other modes in terms of gender. As for age groups, the $36-45$ age group uses each mode more than the other age groups. Individuals with a higher education 
have a higher percentage of car use than those with a lower education. Regarding income, those in the middle-income group (RMB $50 \mathrm{k}-100 \mathrm{k}$ ) are more likely than those in other groups to use each mode.

In the rural context, females are more likely to choose e-bikes for their commutes, as are female urban residents. The 36-45 age group commutes on foot and by bicycle, e-bike, and car more than the other age groups. Unlike in the urban context, individuals with a lower education make more use of cars than those with a higher education. As regards income, those in the middle-income group are more likely to commute by foot or car.

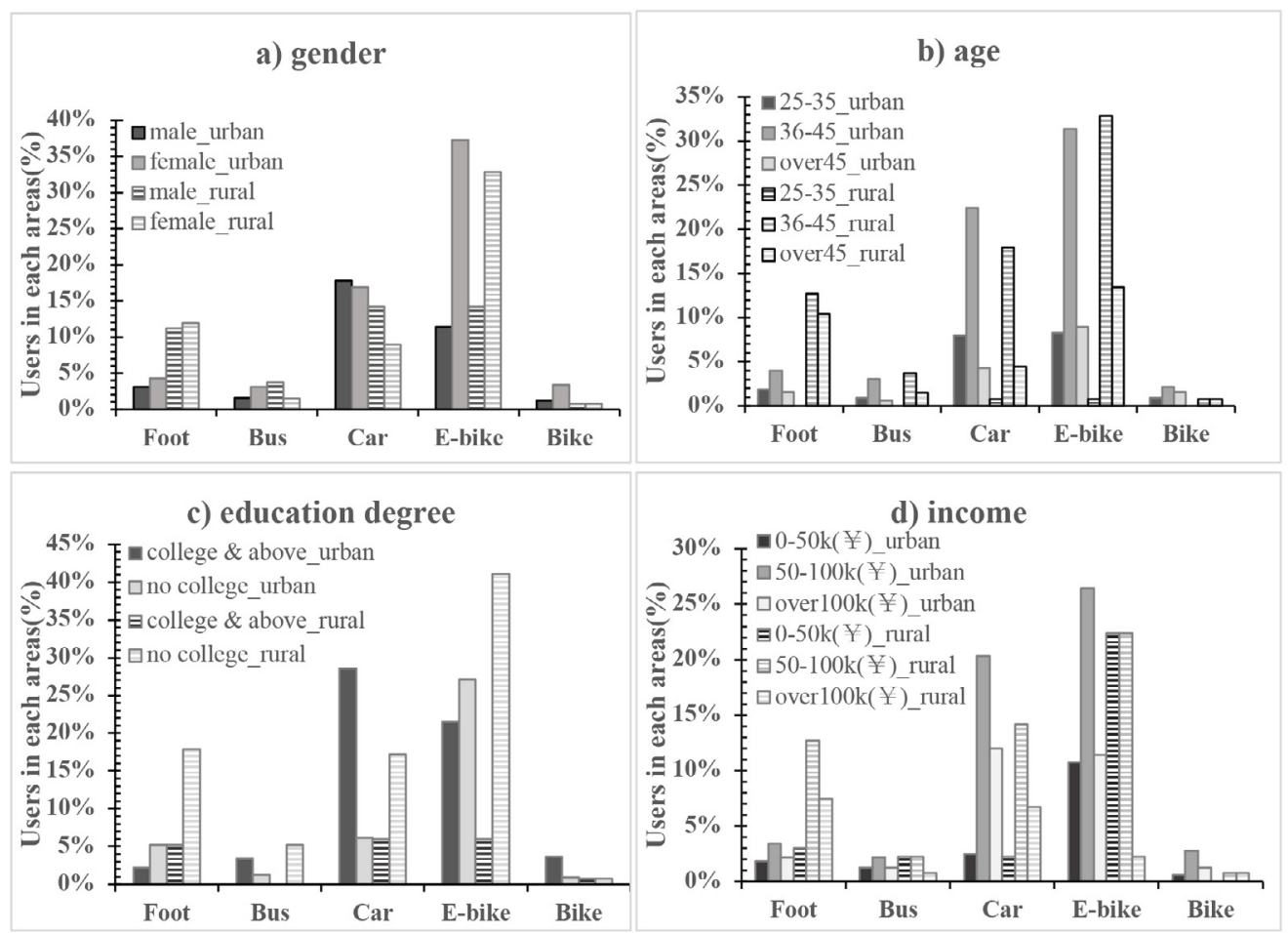

Figure 6. Mode choice of urban and rural residents according to socioeconomics

\subsection{Model parameters}

The model results are shown in Table 3. For trips by any mode, travel time negatively impacts mode choice in general; that is, if a mode entails an increase of one unit of travel time, this has a negative effect on choosing the mode. Regarding socioeconomic attributes, urban residents have a higher propensity to commute to work by bus, bike, or e-bike rather than on foot. The propensity to commute by car is positively associated with urban residents, which is contrary to the situation in the Western context, where both rural and suburban residents have a high propensity to commute by car (Pucher \& Renne, 2005). A possible explanation is that in the Chinese context, urbanization leads to a concentration of more affluent households in cities, leading to higher car ownership rates in cities. This is reflected in car ownership rates in our sample, namely $78.2 \%$ and $47.0 \%$ for urban and rural residents, respectively. Individuals with a higher education prefer to drive a car rather than walk to work. E-bike use is positively associated with individuals with lower incomes (< RMB $50 \mathrm{k}$ and RMB $50 \mathrm{k}-100 \mathrm{k}$ per year), since e-bikes are more affordable than cars for individuals with low incomes. Although traditional bikes are more affordable than e-bikes, both e-bikes (which usually cost RMB 1,500-3,000) and bikes (RMB 
200-800) are affordable for low-income individuals—who, however, still prefer e-bikes, as e-bikes are easier to ride than bikes in terms of the effort required. In addition, e-bike commuting is negatively associated with male individuals, which means that e-bikes are a popular commute mode among females. A possible explanation is that females use e-bikes as a multipurpose mode for picking up children or doing grocery shopping during their commutes, as females play a significant role in looking after family members. The attribute "Return home for lunch" negatively impacts bus choice, which means that bus commuters do not go home for lunch. Combined with the finding that the average bus commute duration was 73.18 minutes in our sample, people use buses for long-distance commuting and do not go home for lunch.

Regarding land-use attributes, higher commercial density at the work location facilitates bus use, but this effect is only found for rural residents. In contrast, urban residents prefer walking to taking a bus if they work in an area with a higher commercial density. This reflects the dual roles of high commercial density at the work location. For rural residents, commercial density at the work location encourages them to commute by bus. In contrast, for urban residents, it probably means compact and more mixed land-use in urban contexts, which decreases commute distance and promotes commuting on foot.

For road attributes, a higher percentage of major trunk roads at the work location encourages individuals to commute by bus or car, which is understandable considering major trunk roads are more suitable for these vehicles. In addition, e-bike commuting is positively associated with the density of major trunk roads and RNBs. One possible explanation is that major trunk roads and RNBs might be the only roads in some areas that are good enough for e-bike use. E-bike commuting is not related to the density of RBs, suggesting that in a local context, e-bike users do not care much about the existence of bike lanes (RBs). RNBs at the work location promote car and e-bike use among rural residents, but much less so among urban residents. This is possibly because RNBs in general are the main road infrastructure that facilitates motorized/semi-motorized vehicle use for rural residents, but this effect is not that strong in the urban context, where high volumes of traffic undermine the positive effect of RNBs on motorized/ semi-motorized vehicle use. Moreover, more foot/bike paths at the work location facilitate bike use. In addition, more active travel intersections at the residential location significantly promote bus use, which reflects that bus use requires a walking environment at the departure location. 
Table 3. Estimation of modeling NL

\begin{tabular}{|c|c|c|c|c|c|}
\hline & Bike & Bus & Car & E-bike & Foot (ref.) \\
\hline & coef.(t-stat.) & coef.(t-stat.) & coef.(t-stat.) & coef.(t-stat.) & coef.(t-stat.) \\
\hline ASC & $-5.59(-5.06)$ & $-3.63(-3.17)$ & $-3.46(-4.56)$ & $-2.39(-3.93)$ & \\
\hline \multicolumn{6}{|l|}{ Trip variables } \\
\hline TT (travel time) & \multicolumn{5}{|c|}{$-0.07(-5.99)$} \\
\hline \multicolumn{6}{|l|}{ Socioeconomic variables } \\
\hline \multicolumn{6}{|l|}{ Location of residence (ref.= rural) } \\
\hline Urban & $2.36(2.75)$ & $1.88(2.13)$ & $3.42(4.69)$ & $2.86(4.65)$ & \\
\hline \multicolumn{6}{|l|}{ Gender (ref.= female) } \\
\hline Male & - & - & - & $-0.94(-3.92)$ & \\
\hline \multicolumn{6}{|l|}{ Education degree (ref. = low) } \\
\hline High & - & - & $0.64(2.36)$ & - & \\
\hline \multicolumn{6}{|l|}{ Income (ref.= > RMB $100 \mathrm{k}$} \\
\hline$<$ RMB $50 \mathrm{k}$ & - & - & - & $0.75(2.36)$ & \\
\hline RMB $50 \mathrm{k}-100 \mathrm{k}$ & - & - & - & $0.36(1.65)$ & \\
\hline \multicolumn{6}{|c|}{ Return home for lunch (ref.= not eat at home) } \\
\hline Eat at home & - & $-2.42(-3.52)$ & - & - & \\
\hline \multicolumn{6}{|c|}{ Land-use attributes (Work location 500-meter buffer) } \\
\hline \multicolumn{6}{|c|}{ Commercial area $($ ref. $=$ commercial $<15 \%)$} \\
\hline Commercial $(\geq 15 \%)$ & $1.66(2.79)$ & $3.42(3.13)$ & - & $0.74(2.29)$ & \\
\hline Commercial $(\geq 15 \%) *$ urban & - & $-3.92(-2.48)$ & - & - & \\
\hline \multicolumn{6}{|l|}{ Industrial area (ref.= Industrial $<10 \%)$} \\
\hline Industrial $((\geq 10 \%))$ & $1.5(1.85)$ & - & - & - & \\
\hline \multicolumn{6}{|c|}{ Road type attributes (Work location 500-meter buffer) } \\
\hline \multicolumn{6}{|c|}{ Major trunk road (ref.= Major trunk road $<10 \%$ ) } \\
\hline Major trunk road $(\geq 10 \%)$ & - & $4.23(4.94)$ & $2.35(3.68)$ & $1.66(2.84)$ & \\
\hline \multicolumn{6}{|l|}{ RNB (ref.= RNB<50\%) } \\
\hline RNB ( $\geq 50 \%)$ & - & - & $2.31(3.4)$ & $1.59(2.89)$ & \\
\hline RNB $(\geq 50 \%) *$ urban & - & - & $-1.89(-2.4)$ & $-1.06(-1.55)$ & \\
\hline \multicolumn{6}{|c|}{ Foot/bike path (ref.= Foot/bike path $<35 \%)$} \\
\hline Foot/bike path $(\geq 35 \%)$ & $1.35(1.84)$ & - & - & - & \\
\hline \multicolumn{6}{|c|}{ Road type attributes (Home location 500-meter buffer) } \\
\hline \multicolumn{6}{|c|}{ Active travel intersection (ref.= Active travel intersection $<75 \%$ ) } \\
\hline Active travel intersection $(\geq 75 \%)$ & - & $1.86(1.92)$ & - & - & \\
\hline Dissimilarity parameter & & & $0.61(0.29,0.9$ & & \\
\hline
\end{tabular}

“_" refers to insignificant variables that were not kept in the model.

Parenthesis with * refers to $95 \%$ confidence interval

Sample size: 459

Init log likelihood: -716.85

Final log likelihood: -326.51

Rho-square: 0.55 


\section{$5 \quad$ Conclusions}

The use of e-bikes by individuals for their daily commute helps to reduce oil dependency and greenhouse gas emissions, but how e-bike use is influenced by the built environment has not been thoroughly examined. This holds in particular for smaller Chinese cities, as most empirical studies in China have addressed big cities. The present research investigated how socioeconomic and built environment factors influence commute mode choice in a small Chinese city and its surrounding rural area, with a focus on e-bike use. The interaction of urban attributes with other factors was included in the analyses in order to explore the position of the e-bike in commute mode choice and to establish the impact of built environment factors in urban and rural contexts on commute mode choice in small cities in China.

In line with the very few earlier findings (Hu et al., 2018), it was found that commuting behavior in small Chinese cities has several distinct characteristics. First, short-distance commuting is a typical characteristic of residents' travel behavior in such cities. For example, the average commute distance in Ganyu is $4.5 \mathrm{~km}$, while in Beijing it is $19.2 \mathrm{~km}$ (China News Service, 2015). In addition, short-distance commuting and relaxed lifestyles make it possible for individuals to go home for lunch, which results in there being a lunchtime commuting peak period in the middle of the day in Ganyu, unlike in big Chinese cities. Second, the commute mode choice in small cities differs from that in big cities: Buses are seldom used, except for long-distance commuting, and the car is not used as the main mode for commuting, especially by rural residents due to the lower availability of cars in rural areas. By contrast, the e-bike is a popular commuting mode: Nearly half (48.15\%) of our respondents commute by e-bike.

The unique commute patterns and popularity of e-bike use in small Chinese cities have their own cultural background. Unlike most Western countries, China is a developing country, and people in China care much less about physical activity and health issues in relation to day-to-day travel; instead, they tend to use the travel modes that can get them to their destinations quickly (Weinert, Ma, \& Cherry, 2007). In addition, riding bikes takes more energy than riding e-bikes, which means that commuters hardly have an enjoyable experience, especially when the weather is bad. This explains why more of our respondents tend to choose e-bikes rather than bikes for their daily commutes. In the developing countries context, people prefer to use the travel mode that has the fastest speed and requires the least effort, which saves time and energy. This cultural background, combined with the smaller geographic size and less developed public transportation system in small Chinese cities, leads to commuters favoring e-bikes.

Moreover, e-bike commuting is more popular among females and low-income groups. In our research, we found that low-income individuals prefer to commute by e-bike, as e-bikes are more affordable than cars. The popularity of e-bikes among females is more associated with the e-bike's mobility characteristics: E-bikes can very easily access various kinds of locations, and this flexible mobility is more desired by females, whose commutes are usually combined with other purposes. In the small city context, the fact that e-bike and car are clustered in the same nested structure of the nested logit model, suggests that the e-bike is similar to the car in terms of functional characteristics. However, our findings concerning the impact of socioeconomic attributes on e-bike use differ from findings in big Chinese cities, where the use of e-bikes is not related to gender and household income (Cherry \& Cervero, 2007). This suggests that the popularity of e-bikes among females and low-income individuals exists only in small Chinese cities.

Regarding the built environment impact, in addition to the elements at residential locations, we also included in our analyses the built environment factors at work locations. We found that the built environment at the destination (work location) rather than at the origin (residential location) has a greater impact on an individual's commute mode choice. This finding is consistent with previous studies in both the American and the European context (Chen, Gong, \& Paaswell, 2008; Maat \& Tim- 
mermans, 2009; M. Zhang, 2004), but differs from findings concerning big Chinese cities (Sun et al., 2017). This is probably because small cities in China are more similar to medium-sized cities in Europe in terms of size and population density, despite being classified in China as "small" cities. In addition, built environment elements in urban and rural contexts have different effects on commute mode choice. A higher commercial density area at the work location facilitates vehicle use for rural residents, while this element inversely decreases bus use and encourages walking by urban residents. Moreover, the presence of certain road attributes (i.e., major trunk roads or city/town roads without bike lanes (RNBs) at the work location) facilitates motorized/semi-motorized vehicle use for residents in the rural area, and this is consistent with findings concerning big Chinese cities, where the high density of main roads promotes car and public transportation use (Zhao, 2013). Finally, we further differentiated the impact of road attributes in urban and rural contexts, and found that the impact of RNBs at the work location on car and e-bike use in the urban area is not as strong as it is in the rural area. This indicates that the impact of the built environment elements differs between the two geographical contexts, and that the urban context could undermine the positive effect of road attributes.

This research had several limitations. As e-bikes are affordable to most Chinese people, we did not gather specific e-bike ownership information but assumed that e-bikes are available to everyone. This also applies to bikes. In addition, the data collection was restricted to students' parents, who are not representative of the whole population of the city and its adjacent rural area. In addition, the research was in the form of a case study. Although some findings are consistent with the very limited research on small Chinse cities (Hu et al., 2018), whether the findings are extrapolatable to other small Chinese cities requires more examination and empirical research. However, these limitations give directions for future research. Future research could conduct a strict random or stratified sampling process based on the spatial distribution of the population in the study area. Moreover, it is important to get insights into attitudes toward different modes of travel by adding some specific questions to a future survey and exploring whether these lead to people's motivations for travel mode choice. The focus could be on whether specific travel attitudes to e-bikes are behind the popularity of e-bikes in small Chinese cities. The health effects related to the use of different travel modes could also be examined in future research.

\section{Acknowledgements}

The present research was sponsored by the Chinese Scholarship Council (CSC) in the form of a PhD scholarship. 


\section{References}

Administration of Quality Supervision of China. (1999). Electric bicycles general technical requirements. Beijing: Standards Press of China.

Aiken, L. S., West, S. G., \& Reno, R. R. (1991). Multiple regression: Testing and interpreting interactions. Thousand Oaks, CA: Sage Publishing.

Asensio, J. (2002). Transport mode choice by commuters to Barcelona's CBD. Urban Studies, 39(10), $1881-1895$.

Campbell, A. A., Cherry, C. R., Ryerson, M. S., \& Yang, X. (2016). Factors influencing the choice of shared bicycles and shared electric bikes in Beijing. Transportation Research Part C: Emerging Technologies, 67, 399-414.

Cao, X. (2015). Examining the impacts of neighborhood design and residential self-selection on active travel: A methodological assessment. Urban Geography, 36(2), 236-255.

Cervero, R. (2013). Linking urban transport and land use in developing countries. Journal of Transport and Land Use, 6(1), 7-24.

Chen, C., Gong, H., \& Paaswell, R. (2008). Role of the built environment on mode choice decisions: Additional evidence on the impact of density. Transportation, 35(3), 285-299.

Cherry, C., \& Cervero, R. (2007). Use characteristics and mode choice behavior of electric bike users in China. Transport Policy, 14(3), 247-257.

Cherry, C. R. (2007). Electric bike use in China and their impacts on the environment, safety, mobility and accessibility. Berkeley, CA: Institute of Transportation Studies.

Cherry, C. R., Weinert, J. X., \& Xinmiao, Y. (2009). Comparative environmental impacts of electric bikes in China. Transportation Research Part D: Transport and Environment, 14(5), 281-290.

Cherry, C. R., Yang, H., Jones, L. R., \& He, M. (2016). Dynamics of electric bike ownership and use in Kunming, China. Transport Policy, 45, 127-135.

China News Service. (2015). Commuting survey of office workers in 50 cities across the country: Average one-way duration is $19.2 \mathrm{~km}$ in Beijing. Retrieved from www.chinanews.com/tp/hd2011/ chart/2015/01-26/31.shtml

Cleary, P. D., \& Kessler, R. C. (1982). The estimation and interpretation of modifier effects. Journal of Health and Social Behavior, 23(2), 159-169.

de Kruijf, J., Ettema, D., Kamphuis, C. B., \& Dijst, M. (2018). Evaluation of an incentive program to stimulate the shift from car commuting to e-cycling in the Netherlands. Journal of Transport Health, 10, 74-83.

Ding, C., Cao, X., Dong, M., Zhang, Y., \& Yang, J. (2019a). Non-linear relationships between built environment characteristics and electric-bike ownership in Zhongshan, China. Transportation Research Part D: Transport Environment, 75, 286-296.

Ding, C., Cao, X., Dong, M., Zhang, Y., \& Yang, J. (2019b). Non-linear relationships between built environment characteristics and electric-bike ownership in Zhongshan, China. Transportation Research Part D: Transport and Environment, 75, 286-296.

European Environment Agency. (2018). Passenger car ownership. Retrieved from https://www.eea.europa.eu/data-and-maps/daviz/passenger-car-ownership-passenger-cars-4\#tab-chart_1

Ewing, R., \& Cervero, R. (2010). Travel and the built environment: A meta-analysis. Journal of the American Planning Association, 76(3), 265-294.

Feng, J. (2017). The influence of built environment on travel behavior of the elderly in urban China. Transportation Research Part D: Transport and Environment, 52, 619-633.

Feng, J., Dijst, M., Wissink, B., \& Prillwitz, J. (2014). Understanding mode choice in the Chinese 
context: The case of Nanjing Metropolitan Area. Tijdschrift voor Economische en Sociale Geografie, 105(3), 315330.

Fishman, E., \& Cherry, C. (2016). E-bikes in the mainstream: Reviewing a decade of research. Transport Reviews, 36(1), 72-91.

Gao, J., Kamphuis, C. B., Dijst, M., \& Helbich, M. (2018). The role of the natural and built environment in cycling duration in the Netherlands. International Journal of Behavioral Nutrition Physical Activity, 15(1), 82.

Goetzke, F. (2008). Network effects in public transit use: Evidence from a spatially autoregressive mode choice model for New York. Urban Studies, 45(2), 407-417.

Handy, S., Heinen, E., \& Krizek, K. (2012). Cycling in small cities. In P. John \& B. Ralph (Eds.), City cycling (pp. 257-286). Cambridge, MA: MIT Press.

Hu, H., Xu, J., Shen, Q., Shi, F., \& Chen, Y. (2018). Travel mode choices in small cities of China: A case study of Changting. Transportation Research Part D: Transport and Environment, 59, 361-374.

Koppelman, F. S., \& Bhat, C. (2006). A self instructing course in mode choice modeling: Multinomial and nested logit models. Washington, DC: US Department of Transportation, Federal Transit Administration.

Lan, T. T. N., Liem, N. Q., \& Binh, N. T. T. (2013). Personal exposure to benzene of selected population groups and impact of commuting modes in Ho Chi Minh, Vietnam. Environmental Pollution, 175, 56-63.

Li, S., \& Zhao, P. (2017). Exploring car ownership and car use in neighborhoods near metro stations in Beijing: Does the neighborhood built environment matter? Transportation Research Part D: Transport and Environment, 56, 1-17.

Lianyungang Bureau of Statistics. (2018). Lianyungang Statistical Yearbook 2018. Beijing: China Statistics Press.

Ling, Z., Cherry, C. R., Yang, H., \& Jones, L. R. (2015). From e-bike to car: A study on factors influencing motorization of e-bike users across China. Transportation Research Part D: Transport and Environment, 41, 50-63.

Maat, K., \& Timmermans, H. (2009). Influence of the residential and work environment on car use in dual-earner households. Transportation Research Part A: Policy \& Practice, 43(7), 654-664.

Mao, Z., Ettema, D., \& Dijst, M. (2016). Commuting trip satisfaction in Beijing: Exploring the influence of multimodal behavior and modal flexibility. Transportation Research Part A: Policy and Practice, 94, 592-603.

Ministry of Public Security of China. (2019). Chinese car ownership has reached more than two hundred million in 2018. Retrieved from http://www.gov.cn/xinwen/2019-01/13/content_5357441. htm

National Bureau of Statistics of China. (2018). China Statistical Yearbook 2018. Beijing: China Statistics Press.

Pucher, J., \& Renne, J. L. (2005). Rural mobility and mode choice: Evidence from the 2001 National Household Travel Survey. Transportation, 32(2), 165-186.

Saelens, B. E., Sallis, J. F., \& Frank, L. D. (2003). Environmental correlates of walking and cycling: Findings from the transportation, urban design, and planning literatures. Journal of Annals of Behavioral Medicine, 25(2), 80-91.

Scheiner, J. (2010). Interrelations between travel mode choice and trip distance: Trends in Germany 1976-2002. Journal of Transport Geography, 18(1), 75-84.

Schwanen, T. (2002). Urban form and commuting behavior: A cross-European perspective. Tijdschrift voor Economische en Sociale Geografie, 93(3), 336-343. 
State Council of China. (2014). State council's decisions on adjusting the standards for dividing cities. Retrieved from http://www.gov.cn/zhengce/content/2014-11/20/content_9225.htm

Sun, B., Ermagun, A., \& Dan, B. (2017). Built environmental impacts on commuting mode choice and distance: Evidence from Shanghai. Transportation Research Part D: Transport and Environment, 52, 441-453.

Susilo, Y. O., \& Maat, K. (2007). The influence of built environment to the trends in commuting journeys in the Netherlands. Transportation, 34(5), 589-609.

Wan, Z., Wang, X., \& Sperling, D. (2013). Policy and politics behind the public transportation systems of China's medium-sized cities: Evidence from the Huizhou reform. Utilities Policy, 27, 1-8.

Wang, D., \& Chai, Y. (2009). The jobs-housing relationship and commuting in Beijing, China: The legacy of Danwei. Journal of Transport Geography, 17(1), 30-38.

Wang, D., Chai, Y., \& Li, F. (2011). Built environment diversities and activity travel behavior variations in Beijing, China. Journal of Transport Geography, 19(6), 1173-1186.

Wang, D., \& Zhou, M. (2017). The built environment and travel behavior in urban China: A literature review. Transportation Research Part D: Transport and Environment, 52, 574-585.

Wang, H., Fu, L., Zhou, Y., \& Li, H. (2008). Modelling of the fuel consumption for passenger cars regarding driving characteristics. Transportation Research Part D: Transport and Environment, 13(7), 479-482.

Weinert, J., Ma, C., \& Cherry, C. (2007). The transition to electric bikes in China: History and key reasons for rapid growth. Transportation, 34(3), 301-318.

Weiss, M., Dekker, P., Moro, A., Scholz, H., \& Patel, M. K. (2015). On the electrification of road transportation: A review of the environmental, economic, and social performance of electric twowheelers. Transportation Research Part D: Transport and Environment, 41, 348-366.

Wen, C.-H., Wang, W.-C., \& Fu, C. (2012). Latent class nested logit model for analyzing high-speed rail access mode choice. Transportation Research Part E: Logistics and Transportation Review, 48(2), 545-554.

Yang, Q., Yuan, H., \& Feng, S. (2014). Travel characteristics of rural residents under different economic condition (In Chinese). Journal of Chang'an University (Natural Science Edition), 34(1), 76-83.

Zhang, C., Chen, X., Huang, W., \& Yu, P. (2014). Has the legacy of Danwei persisted in transformations? The jobs-housing balance and commuting efficiency in Xi'an. Journal of Transport Geography, 40, 64-76.

Zhang, M. (2004). The role of land use in travel mode choice: Evidence from Boston and Hong Kong. Journal of the American Planning Association, 70(3), 344-360.

Zhang, S. (2018). Chinese e-bike ownership has reached 250 million. Retrieved from http://industry. people.com.cn/n1/2018/1028/c413883-30367100.html

Zhang, Y., Yao, E., Zhang, R., \& Xu, H. (2019). Analysis of elderly people's travel behaviors during the morning peak hours in the context of the free bus program in Beijing, China. Journal of Transport Geography, 76, 191-199.

Zhao, C., Nielsen, T. A. S., Olafsson, A. S., Carstensen, T. A., \& Meng, X. (2018). Urban form, demographic and socio-economic correlates of walking, cycling, and e-biking: Evidence from eight neighborhoods in Beijing. Transport Policy, 64, 102-112.

Zhao, P. (2013). The impact of the built environment on individual workers' commuting behavior in Beijing. International Journal of Sustainable Transportation, 7(5), 389-415. 